\title{
Project Management using Agile Frameworks
}

\author{
Elena MIRCEA \\ Bucharest University of Economic Studies, Romania \\ elenamircea94@gmail.com
}

The evolution of IT market brings us complex technologies which can go beyond the processing power of the human brain. Daily processes and business activities were modified, some of them being completely removed from the industry, so the society had to accept the changes and to adapt to the new values and principles. Every person must develop new skills, trying to find better ways of doing the day by day work. The aim of this paper is to present "Agile" as an innovative way of thinking in a challenging world, beside all the principles and practices that define it. In this study, the most important agile methods and methodologies (Scrum and Kanban) will be presented, discovering similarities, differences, but more important how they can work together.

Keywords: Agile, Scrum, Kanban, Scrumban, Project Management.

DOI: $10.12948 / \mathrm{ei} 2019.01 .04$

\section{1} Introduction

Software development has known various stages, but only in the '70s some general rules were established under a generic name. Over the years, in software development were implemented several models, starting with "Code and Fix" approach in which the team wrote the code and all the bugs were solved in the end. The application was delivered to the end customer and even the smallest changes were difficult to implement, as in some cases the whole program had to be modified. In the mid-1950s specific steps were defined, stages that had to be followed by each software development team: client requirements, design, development, integration, testing and deployment. This methodology became known as "Waterfall" model in 1970 and it is still used today in many projects. The principle behind the model is based on dividing the program in more phases and starting to work at the first one. After this is finished, the team can start to work on the next phase, but going backward for extra changes is very difficult, losing time and money. All the customer requirements are established from the beginning, so any modification comes with a high impact for the development team. Also, the customer involvement is quite limited during the development. In 10 years, another model was released, called "Spiral" and it is the first one that introduced terms like iterative and incremental. In the '90s the idea of frequent feedback started to grow and an alternative to the Waterfall model appeared, "Rapid Application Development".

In 2001 the agile methodology was clearly defined by a group of developers, which understood the importance of learning from the previous iterations and from their own mistakes. In no more than 68 words they described the most important values of agile and pointed the principles which help obtaining high value software. The basic idea suggests setting on a second place the time-consuming processes and increasing the human interactions. [1] "Agile" is mainly used in the IT industry, for defining a Project Management methodology, but sometimes it is wrongly believed that only in IT this model works. The agile practices can be used in every industry, from human resources to financial departments and even in the day by day life activities. The agile processes help the team to work after their own rules, improving the model based on the constant feedback. Each team member has the opportunity to get involved and expose his idea. The special feature which distinguishes the agile software development from any other model is the way in which the product is delivered, after each step the customer can find new functionalities in the application. A flexible, dynamic and client focus product is provided to the end user. 
2. Agile Work - Rituals, Concepts, Instruments

In literature [2], agile is considered more as a culture, rather than just a way of work, so several key concepts need to be known in order to be able to use the agile methods. First, all the team members are equals, positions are not clearly defined. Everyone can be a developer, tester, analyst at any point in time if this is needed. According to ,The $13^{\text {th }}$ annual State of Agile Report" [3], Scrum is the most popular agile method; daily activities are based on the past experiences and not only on theoretical aspects. In [4], Scrum is described as an iterative and incremental way of work (figure $1)$.

\section{Task List $\rightarrow$}

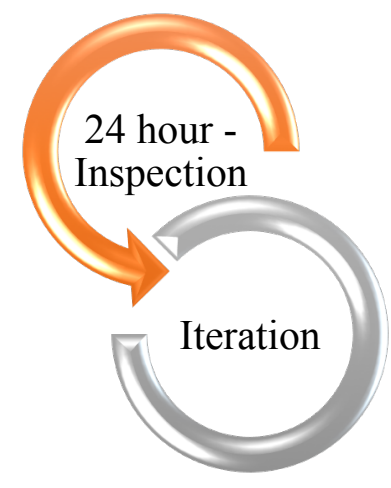

$\rightarrow$ Increment of functionalities

Fig. 1. Scrum Skeleton in Schwaber opinion

Another popular agile method is Kanban which is based on limiting work in progress, visualising work, managing flow by making process policies explicit and implementing feedback loops. [5] This model is borrowed from Toyota, meaning sign board or signal card and ensures that the factory will not produce more that is needed, eliminating waste. Besides Scrum and Kanban, other metrologies were developed, like [6]:

- Extreme Programming (next to Pair Programming were two people are working together, method being based on simplicity, continuous feedback and high-quality software delivered to the customers);

- Feature-driven development (contains five basic activities - develop overall model, build feature list, plan by feature, design by feature and build by feature);

- Adaptive system development (project should adapt continuously to the required changes);
- Lean Software Development (based on eliminating waste, constant learning and empowering the team);

- Crystal Clear (recommended for bigger teams and focused on people, not on processes).

In practice, Scrum and Kanban are the most used and discussed of all the agile methods, so the paper will concentrate further on those methodologies and ways in which they can be combined.

\subsection{Scrum}

Scrum was developed by Ken Schwaben and Jeff Sutherland in the early ' 90 s and is considered to be a framework for developing, delivering and sustaining complex products. In order to define Scrum, all the roles, events, artefacts and rules have to be known and understood. Scrum base is considered to be formed from five values (figure 2). 


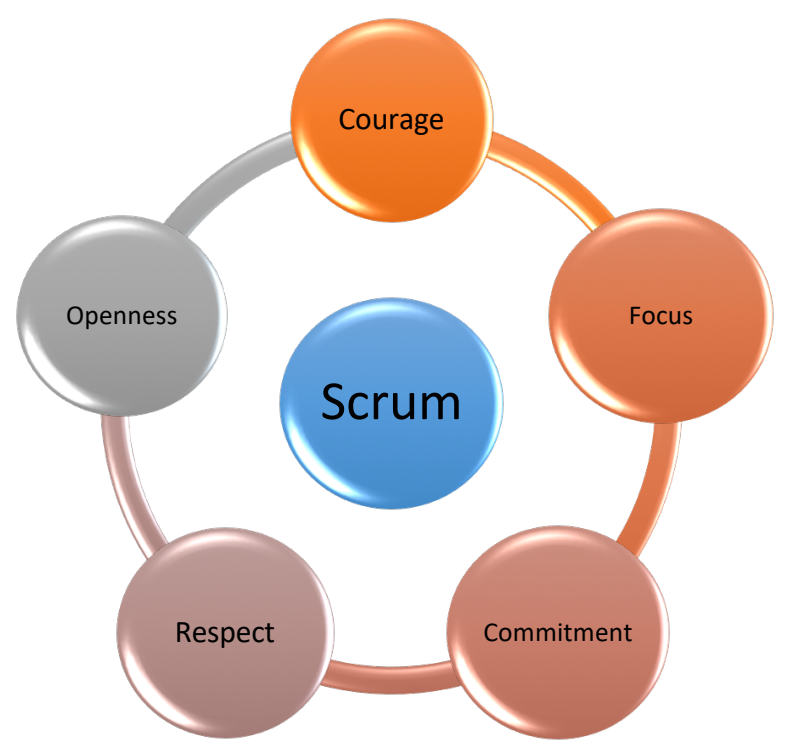

Fig. 2. Scrum Values

Agile teams are small and self-directed, the tasks are distributed taking into consideration the project needs. The following roles are defined:

- Stakeholder - financially affected by the result (client);

- Product Owner - the customer himself or someone who represents his needs and interests; each team has one PO which prioritize the tasks, takes care of the budget and knows all the functionalities that have to be implemented;

- Scrum Master - can be considered as a team leader, has very good agile skills and is the owner of the agile meetings

- Delivery Team - the main goal is to deliver on time, according to the agreed standards.

According to "The Scrum Guide", the Scrum Team consists of a Product Owner, a Scrum Master and the Development Team which has between three and nine members. [7] Scrum Teams are self-organized and cross-functional being focused on choosing the best way to accomplish the work and having all the needed competences for this.

The team must deliver after each iteration, which is a fix period of time (2, 3 or 4 weeks) called sprint in Scrum. Every two or three months a release is scheduled, and new functionalities are taken into production. Releases and sprint duration are set from the beginning can cannot be modified during an iteration.
Specific concepts are defined and without knowing them a new member cannot integrate in the team: [8]

- User Stories - customer requests, which will be used as task: As a user/customer, I want to <action> so that <benefit>. (Should be independent and valuable actions, testable and dimensioned for one sprint.);

- Story Points - unit measure for user story, can be considered an estimation of the work;

- Product Backlog (Master Story List) - list containing all the user stories, owned by the PO. "As long as a product exists, the Product Backlog also exists" [4];

- Sprint Backlog - tasks which will be executed during one sprint.

Communication is a base element in project management, so as part of the agile methods, some rituals were defined, and meetings that take place regularly: [8]

- Sprint Planning - defining user stories for the next sprint (Delivery Team and Scrum Master);

- Daily Stand-up - 15 minutes daily meeting, discussing what was done in the previous day, what will be done today and the impediments encountered (Delivery Team and Scrum Master); 
- Sprint Review - team presents what was delivered over a sprint (Product Owner, Delivery Team and Scrum Master);
- Retrospective - lessons learned, meeting done after a sprint (figure 3). (Delivery Team and Scrum Master).

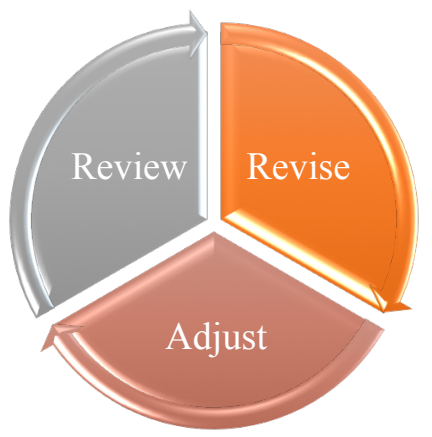

Fig. 3. Lessons learned

As in management everything must be transformed into a number, KPIs which confirms if a project is profitable or not were defined also in agile, some metrics that calculates the performance of the teams. One of them is velocity, which refers to the number of story points that were delivered over a sprint. Another one is the Minimum Viable Product (MVP) which follows the minimum product that meets the client's expectations. Refers to everything that the program must have and not to what would be nice to have. Always the funnel of work must be prioritised and each member has to work at one task at a time, this way he will be concentrated over just one think. Implementation of agile methods in an organization involves using some specific tools that help teams visualize their work. [2] It is important to know if the team is distributed or not, since different approaches must be followed. It is compulsory to use burn down charts and agile boards when working agile, in order to see what needs to be done, the work in progress and what was already done. Each team can choose between the classic way, with sticky notes and panels on the walls or technology by using specific tools (Jira, Trello, Wrike etc.).

Distributed teams cannot be managed as locals, every team member must permanently see the agile table. Using paper sheets or internal tools in such cases will only ensure the failure of the project. Successfully distributed teams are conducted by some simple rules. [2] Remote colleagues do not have to be treated as if they were locals and it is valid also the other way around. Geographically speaking, if latitude is acceptable, as the team members are coming in the office at the same hour, longitude should not be accepted, or at least with no big differences. The company must invest in appropriate tools, but also should permit business travels. It is recommended that all the members of a team meet at least for one of the usual meetings per sprint.

Even if using distributed teams is not recommended in agile, $78 \%$ for the agile companies admit that they work using such teams. [3]

\subsection{Kanban}

Kanban as a working method, was invented by Toyota and helped the manufacturer to eliminate waste by keeping the number of unused parts at a level that help maximize flow and minimize the number of manufactured parts. David J Anderson is the one that brought this technique in IT after a visit to the Imperial Garden of Tokyo were every visitor received a ticket that had to be returned at the exit. $\mathrm{He}$ realized that this way the number of visitors is kept under control, being under a certain limit [5]. Similar problems were discovered in software development, too many tasks in parallel, cause bad quality in products and late delivery to the customers.

The method is described by four principles:

- Start with what must be done now;

- Changes are made gradually;

- Respect current roles and responsibilities;

- Encourage leadership at any hierarchical 
level.

Kanban works on an organizational level for big and small companies, but also on a personal level and the advantage of this technique is that the old practices do not have to be completely removed, but adapted to the new rules. Next to the principles, Kanban comes with six practices that give directions for implementing this new working method in a team [5]:

- Visualising the work (figure 4) - the team must constantly see the steps that have to be performed during the process. This is possible by using some boards (electronic or physical), called Kanban boards, on which the progress must be counted. Each column represents one step in the developing process. In the "Future" column, the tasks are unsorted, only in the second one they are arranged by different standards defined by the team.

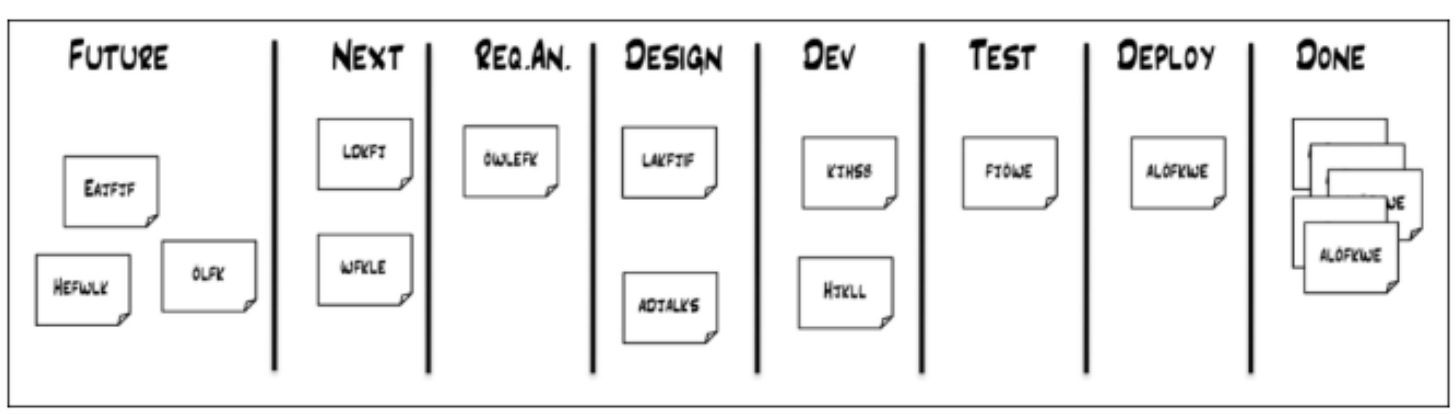

Fig. 4. Kanban board for visualizing the work [5]

- Limiting work in progress (WiP) - limits are added to each column, meaning that the maximum number of tasks that can be executed in parallel cannot be bigger than the limit (figure 5). According to Lean philosophy, unfinished work is one of the biggest waists for every production system.

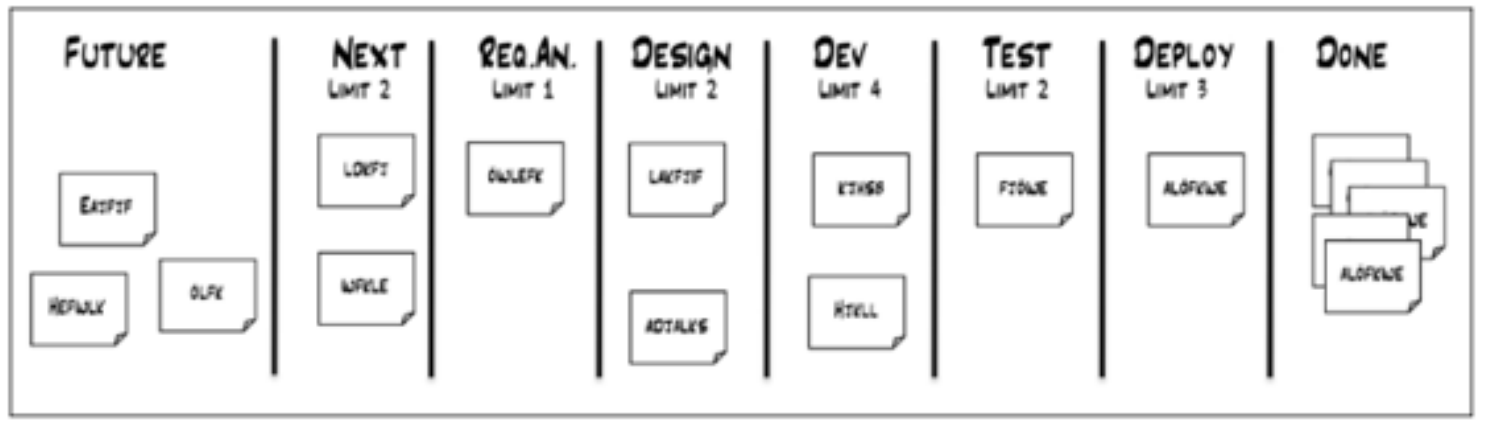

Fig. 5. Kanban board with WiP [5]

- Managing flow - the flow of the process must be improved, so the lead-time or time-to-market has to be decreased. Leadtime is usually calculated from when the team starts to work on an item until it gets in production, but can also be measured from when the item is requested until deployment (figure 6). This represents the point from where the organization must be changed together with the working way. In Kanban was defined a term to measure also the actual time spent by a development team on a task, called cycle time. 


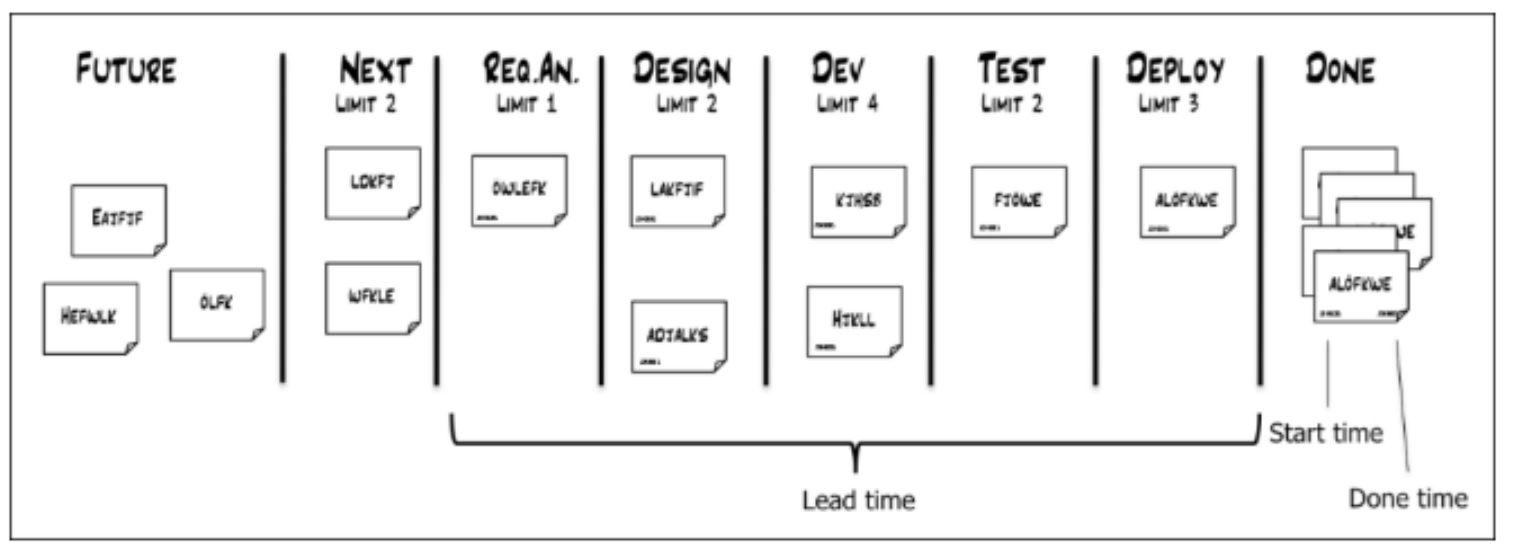

Fig. 6. Kanban board containing WiP and lead-time [5]

- Making process policies explicit - everyone must know all the processes, policies and practices in order to suggest improvements.

- Implementing feedback loops - delivering fast is not everything, as the quality of the product is very important. Feedback should come from other persons inside the team, but also from the customer, to make sure that in the end the deliverable will correspond with his expectations.

- Improving collaboratively, evolving experimentally - use model and the scientific methods (Lean, chaos theory, gaming theory)

Kanban principles and practices are based on a management philosophy called Lean. This philosophy is also developed by Toyota and concentrates on understanding the things that generates extra costs, besides human resources and elements included in production. For software development these costs can be found in design documents and code that have not been released in production. The cost has been done, but the effort is not rewarded. [9]
The same as Agile, lean is considered to be a way of thinking and is described in 14 principles based on long-term thinking, focus on quality and streamlining the process flow. The idea is to lower the risk for unused products by shortening the time to market or the time to get feedback, just to be sure that the work is well done and things look as expected from the customer perspective.

Tomas Björkholm noticed in [5] that in the European and American organizational cultures, people tend to believe that the way in which they are doing a certain job is the best. Otherwise, in Japanese culture every week they try to be better than in the week before, in order to stay in business as long as possible.

\subsection{Scrum vs. Kanban}

Even if Scrum and Kanban are both considered Agile frameworks, having common ideologies, the approach is different for each of them (table 1). While Scrum comes with very strict rules and rituals, Kanban offers freedom in choosing the way of working and organising the team.

Table 1. Scrum vs. Kanban - differences (adaptation after [10])

\section{SCRUM}

Roles must be changed according to the new Keeping the current roles and responsibilities principles and practices

Cross functional teams, any member can help with any task

Completely change the old processes

Rituals, meeting planned from the beginning

Timeboxed iterations (2-4 weeks)
Dedicated teams, specialized people that can help in other fields if they have the knowledge

Start for the current processes and adapt them the team wants

Continuous work No planned rituals, meeting scheduled when 


\begin{tabular}{|l|l|}
\hline Measuring progress - Velocity & Measuring progress - WiP \\
\hline Task estimation - mandatory & Task estimation - optional \\
\hline Prioritizing the backlog before each sprint & Task prioritization not required \\
\hline Scrum board is reset after each sprint & Kanban board is persistent \\
\hline
\end{tabular}

According to the agile principles, communication and adaptation to the changes are essential, helping the team to constant deliver functional software. Working methods may differ, but similarities appeared between the two frameworks:

- Common mission, eliminating the waste and obstacles;

- Self-organizing teams, without a teamleader responsible for task assignment;

- Visualizing the work in progress (Scrum/Kanban boards);

- Constant delivery of functional software;

- Processes and practices are improved and transparent.
When working according to the agile techniques, a clear delimitation is not done every time, so hybrid methods appeared. Usually, even when using Kanban, daily meeting are scheduled in order to see the progress or feedback meetings to find the impediments, but they do not have a special name or predefined durations.

In literature, a new concept was defined, Scrumban [11], which is an adaptable model to the team needs. Based on two values, Scrumban use the principles and practices from Scrum to be agile and process improvement from Kanban to allow teams to evolve (table 2).

Table 2. Scrum vs. Kanban vs. Scrumban (adaptation after [12])

\begin{tabular}{|c|c|c|c|}
\hline & Scrum & Kanban & Scrumban \\
\hline Instruments & $\begin{array}{l}\text { Scrum board, Burn- } \\
\text { down charts, priori- } \\
\text { tized task lists }\end{array}$ & Kanban board & $\begin{array}{l}\text { Working board for } \\
\text { visualizing the work- } \\
\text { flow and the pro- } \\
\text { gress }\end{array}$ \\
\hline Roles & $\begin{array}{l}\text { Well defined (Prod- } \\
\text { uct Owner, Scrum } \\
\text { Master, Develop- } \\
\text { ment Team) }\end{array}$ & No prescribed roles & $\begin{array}{l}\text { Team and other } \\
\text { needed roles }\end{array}$ \\
\hline Planning meeting & $\begin{array}{l}\text { Mandatory, Sprint } \\
\text { Planning }\end{array}$ & $\begin{array}{l}\text { If team wants and } \\
\text { the flow is improved }\end{array}$ & $\begin{array}{l}\text { If team wants and } \\
\text { the flow is improved }\end{array}$ \\
\hline Daily meeting & $\begin{array}{l}\text { Mandatory, every } \\
\text { day for } 15 \text { minutes }\end{array}$ & No meeting & $\begin{array}{l}\text { Recommended, for } \\
\text { continuous work on } \\
\text { requirements and re- } \\
\text { duce idle time }\end{array}$ \\
\hline $\begin{array}{l}\text { Review/Retrospec- } \\
\text { tive meeting }\end{array}$ & $\begin{array}{l}\text { Predefined meetings, } \\
\text { activities and dura- } \\
\text { tions defined by the } \\
\text { framework }\end{array}$ & Not prescribed & $\begin{array}{l}\text { Can be done when } \\
\text { needed for process } \\
\text { improvement and } \\
\text { feedback }\end{array}$ \\
\hline Progress & $\begin{array}{l}\text { Velocity (sprint con- } \\
\text { tent) }\end{array}$ & $\begin{array}{l}\text { WIP (task limit for } \\
\text { each step) }\end{array}$ & $\begin{array}{l}\text { Controlled by work- } \\
\text { flow state }\end{array}$ \\
\hline Product Backlog & $\begin{array}{l}\text { List of prioritized } \\
\text { and estimated sto- } \\
\text { ries, using story } \\
\text { points }\end{array}$ & $\begin{array}{l}\text { Task list, each task } \\
\text { containing a signal } \\
\text { card }\end{array}$ & $\begin{array}{l}\text { Signal card/Time } \\
\text { card }\end{array}$ \\
\hline Iterations & 2-4 weeks (Sprint) & Continuous flow & Continuous flow \\
\hline
\end{tabular}




\begin{tabular}{|l|l|l|l|}
\hline Estimations & Story points & $\begin{array}{l}\text { Nu estimations, each } \\
\text { task has a signal } \\
\text { card }\end{array}$ & $\begin{array}{l}\text { No estimations over } \\
\text { the tasks }\end{array}$ \\
\hline
\end{tabular}

Scrum diagrams and meetings help finding the problems in the existing processes and offer opportunity of constant improvement (kaizen), but when the team is mature enough the attention is captured by lead time and cycle time together with the delivery time. A fixed number of tasks that goes in the next iteration is set (WiP), so estimation using Scrum methods is not used anymore. At a cultural level, the elements are taken from Kanban and the practices from Scrum to minimize losses, improving processes by adapting them to the team needs.

In [3], a top of the benefits of adopting agile was done on a diverse set of organizations sizes $(46 \%$ of respondents from organizations of more than 5000 people), geographic locations (53\% respondents from outside North America), roles and industries. $97 \%$ of respondents report that agile is used in their organizations.

On the first five positions the following answers were reported: [3]

- Ability to manage changing priorities (69\%);

- Project visibility (65\%);

- Business/IT alignment (64\%);

- Team morale (64\%);

- Delivery speed/Time to market (63\%).

\section{Agile Simple Practices in Project Man- agement}

Agile model does not come with too many rules or restrictions, but it is recommended to follow the basic principles while working this way. In [2] this methodology was defined in an interesting way and were shown different approaches that can be followed without overwhelming the team. Agile is about simplicity and for any problem a simple solution should be found:

- When the team meets for the first time some general rules are set, about people behaviour, actions that are acceptable or not inside the team. These are written on sticky notes and placed in a visible place. This represents the social contact of the team and whoever breaks the rules has to speak in front of the team.

- The agile team must be constantly motivated, so the general atmosphere should be known. In the classical approaches, surveys are popular, in this case a simplified method is used, by having a jar and some smalls balls in two colours (e.g. black and white). Every morning the employee chooses a ball and puts it in the jar. At the end of the day, the manager can see if the team is happy or not by analysing the jar and finding the predominant colour.

Communication can be considered the base of project management, especially in agile. In order to collaborate, is crucial for the teams to freely express their ideas, but with respect for the others. The main questions in agile becomes "How can I do it better/faster?", every time the process must be improved by obtaining a better time or better quality of the product. Four human values were identified as being the agile values, the ones that stay above of all the practices (figure 7). 


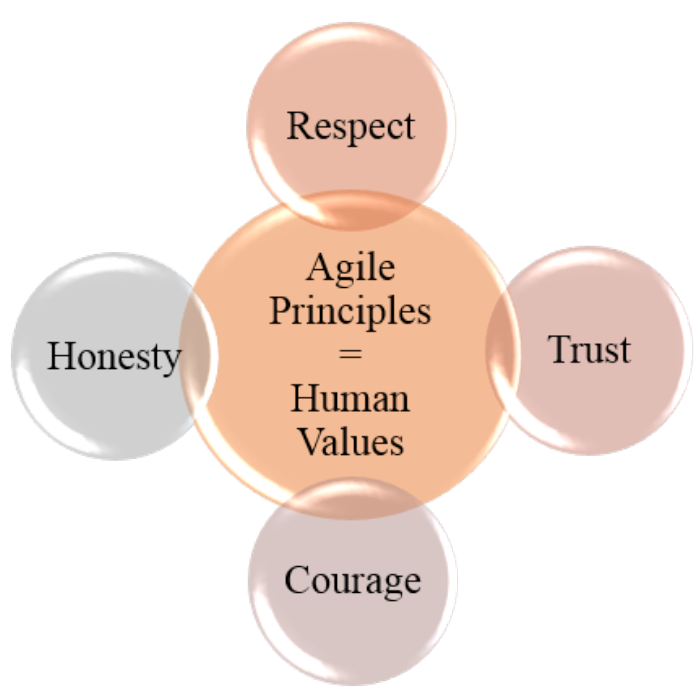

Fig. 7. Agile Values according to [2]

Agile is a way of work based on a set of values and principles:

- Clearly define the outcome, focus on the result and less on organizing the team;

- Work and learn based on repetition - listen, iterate, learn and correct;

- Self-organized and small teams.

The consultant Patrick Lencioni described in [13] the five dysfunctions of a team by analysing the dynamic inside of a group and gathering the common mistakes, offering solutions to improve team performance (figure 8). Key concepts like trust and fear of conflict were disposed in a pyramidal form trying to emphases the management mistakes that are done in a company. Since sharing ideas is not encouraged during business meetings, people are afraid of commitments when things are not clear. According to Lencioni, because of these common faults, in the end, no results are obtained since no common purpose was agreed inside the team.

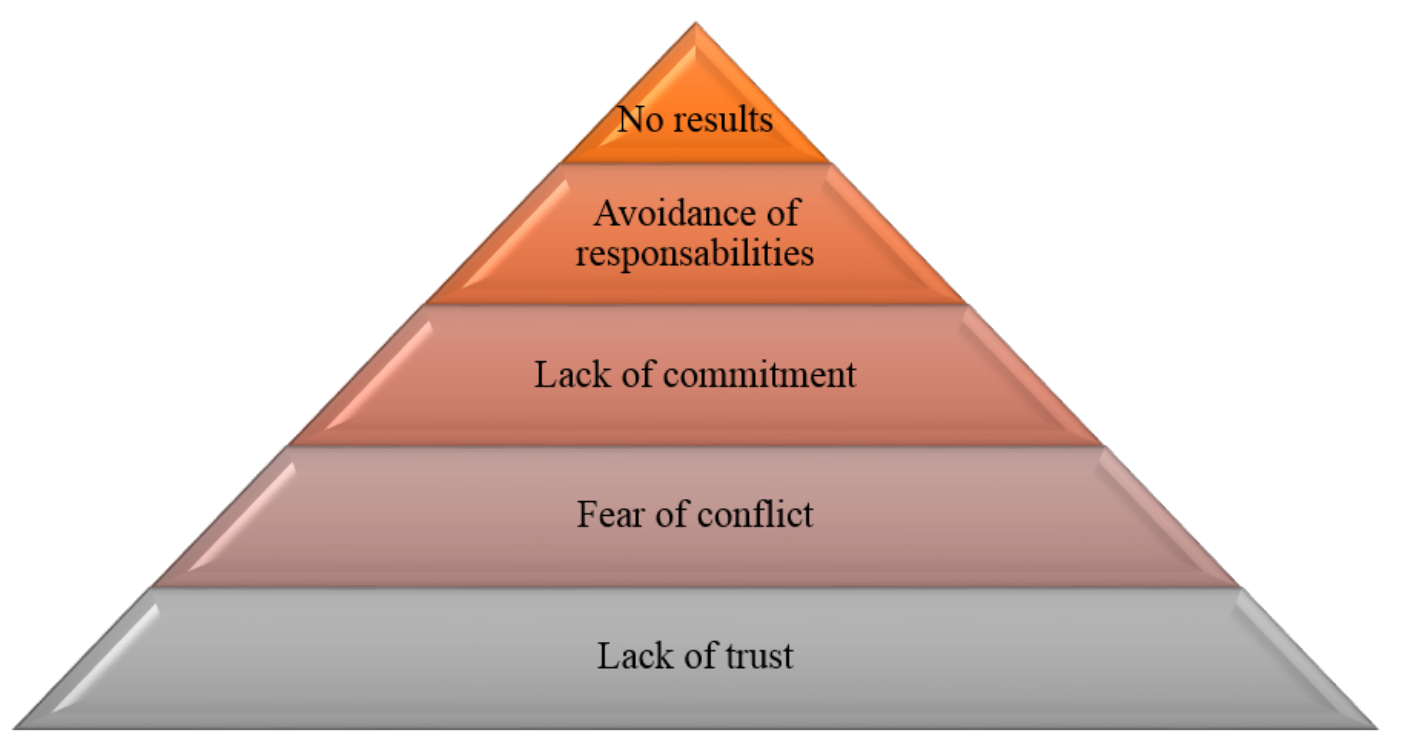

Fig. 8. The five dysfunctions of a team

Agile processes and practises have to be followed and respected by the whole team and every step described in books must be implemented, every meeting has to take place. As Schwaber recommended in [4] changes in the processes are not allowed, especially in the beginning, when teams are learning how to manage the new roles and responsibilities. After years, for mature teams, when it is considered that the knowledge is strong enough, 
modifications can be done, and methods can be adapted depending on the needs. This method learning, called Shu-Ha-Ri (followbreak-transcend), is originally from Japan and became very popular in agile, describing the stages known by a team during the years. [14]

- "Shu" is the first phase, when the team members collaborate for the first time, they are just following the agile rules without ignoring any of the practices.

- "Ha" is the intermediate stage, some behaviours and habits are already formed and accepted by the whole team and if some more freedom is needed, small adjustments can be done to the standard processes.

- "Ri" describes a team that has many years of experience, each member can learn from his own experience and adapt the knowledge for the project. Even in this case, a very small change has to be discussed and agreed with the whole team.

Above all the rules and principles developed in agile, some myths were formed, and it is wrongly supposed that standard activities from the classical way of working do not exist here. Documentation exists in agile, the only difference is that it is not written in the beginning on the project, but only after all the things are clearly defined. As in this methodology, communication is over any written document. First, the team members, together with the customers review the product and then specifications can be documented. This way, rework is avoided, and the workflow approval is shortened.

\section{Conclusions}

In conclusion, agile is a set of values, principles and practices that will change behaviours, redefining the way of work, by visualising it as a new culture and less as overwhelming processes. When developing software using agile methods the team starts the iteration by evaluating what should be done, then selecting and transforming a potential functionality in the increment needed in the end.
Scrum is the most common agile methodology and it comes with major changes for the company, introducing new rules and terms and eliminating the classical management methods. The agile team has the power and the methodology must be followed together with all the meeting, estimations and prioritizations needed, delivering functional software by the end of each sprint. Kanban comes with more freedom, eliminating the unnecessary processes, but emphasising the fact that only a mature team can be fully capable of accepting the success and the failure with openness.

In the last years, Scrumban has become an alternative for Scrum and Kanban due to the flexible processes and principles that can be easily adapted to the organizational culture of the companies. The agile practices are valid for all the agile teams, regardless the methods used, as agile is more as a vision based on human values.

It is wrongly believed that things are unorganized or unplanned in agile. Taking into consideration all the rituals that must be followed, all the tools that should be used, can be said that agile methodologies brings order and innovation for human resources more than any other method. Flexibility does not mean that the project is not organised, but only comes with some benefits for the employees by letting them propose new ideas and express their feelings. Changing roles is not similar with chaos, it means that everyone has the opportunity to learn different things and see the daily work from a different perspective.

Regardless the field of activity that defines a company, a good project manager should be characterized by openness, this is the reason why agile practices are not viable only for IT projects. Daily meetings or retrospectives are welcome in any office if the people want to improve the business. Of course, agile does not solve all the problems, but comes with solutions which can be applied in all the cases. As long as the people are willing to collaborate and communicate, the work environment becomes a place where every person can evolve by learning new skills and sharing knowledge. 


\section{References}

[1] Kent Beck, Mike Beedle, Arie von Bennekum, Alistair Cockburn, Martin Fowler, James Grenning, Jim Highsmith, Andrew Hunt, Ron Jeffries, Jon Kern, Brian Marick, Robert C. Martin, Steve Mellor, Ken Schwaber, Jeff Sutherland and Dave Thomas, "Manifesto for Agile Software Development," 2001. [Online]. Available: This declaration may be freely copied in any form, but only in its entirety through this notice..

[2] IBM Agile Explorer, "Think Academy," 2018 (last update). [Online]. Available: https://agile-ibm.myblue-

mix.net/courses/taste-of-agile/agile-principles-values-and-behaviors. [Accessed 23 November 2018].

[3] "The 13th annual State of Agile Report," 6 Mai 2019. [Online]. Available: https://www.stateofagile.com/\#ufh-c473508-state-of-agile-report.

[4] K. Schwaber, Agile Project Management with Scrum, Microsoft Press, 2004.

[5] T. Björkholm and J. Björkholm, Kanban in 30 days, Packt Publishing, 2015.

[6] "What's the difference? Agile vs. Scrum vs. Waterfall vs. Kanban," 2016. [Online]. Available: https://www.smartsheet.com/agile-vs-scrum-vs-waterfallvs-kanban.

[7] Ken Schwaber and Jeff Sutherland, "The Scrum Guide," November 2017. [Online].
Available:

https://www.scrumguides.org/scrum-guide.html.

[8] Mauricio Rubio, "An Agile Crash Course: Agile Project Management and Agile Delivery," 27 June 2018. [Online]. Available: https://learning.oreilly.com/home/.

[9] M. E. O. Boiser, "Kanban Fundamentals," Technics Publications 2018, 2018. [Online]. Available: https://learning.oreilly.com/videos/kanban-fundamentals/9781634623650/978163462365097816346236506 .

[10] "How to choose between Agile and Lean, Scrum and Kanban - which methodology is the best?," [Online]. Available: https://miro.com/blog/choose-betweenagile-lean-scrum-kanban/\#.

[11] Marian Stoica, Bogdan Ghilic-Micu, Marinela Mircea and Cristian Uscatu, "Analyzing Agile Development - from Waterfall Style to Scrumban," Informatica Economica, vol. 20, 2016.

[12] "Agile Alliance," 2017. [Online]. Available: https://www.agilealliance.org/what-is-scrumban/.

[13] Patrick Lencioni, The Five Dysfunctions of a Team, John Wiley \& Sons, Inc., 2002.

[14] Luis Goncalves, Organisational Mastery - The blueprint to create effective, efficient and highly rewarded executive leaders, evolution4All.

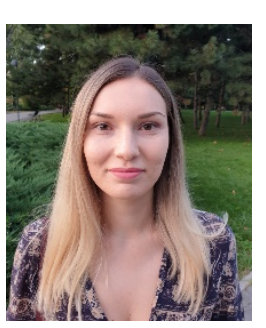

Elena MIRCEA has graduated the Faculty of Cybernetics, Statistics and Economic Informatics in 2016. In 2018 she has graduated the Informatics Systems for the Management of Economic Resources and Processes Master program and currently pursues a $\mathrm{PhD}$ in Economic Informatics at the Bucharest University of the Economic Studies. She worked as a SAP Specialist at IBM Romania and is currently working as a SAP FI Consultant at American Greetings. Her research interests are: Agile, Project Management and Information Sys-

tems. 